\title{
PERANCANGAN DAN PENERAPAN SISTEM PEMOMPAAN AIR SAMPEL UNTUK SISTEM ONLINE MONITORING KUALITAS AIR SUNGAI
}

Design and Application of The Water Sample Pumping System for Online River Water Quality Monitoring System

Oleh:

Galih Setiaji dan Heru Dwi Wahjono

Pusat Teknologi Lingkungan, BPPT

\begin{abstract}
Abstrak
Studi pengkajian dan penerapan Sistem Online Monitoring Kualitas Air di Sungai Ciliwung yang telah dilakukan oleh BPPT dan KLHK pada tahun 2014, menghasilkan rekomendasi untuk dibangunya sistem pengambilan sampel air pada kondisi sungai tertentu. Sistem pengambilan sampel ini berfungsi untuk memompa air dari sungai menuju tangki sensor sehingga sensor tidak perlu dicelupkan langsung ke dalam sungai. Tujuan dari sistem pengambilan sampel ini adalah untuk menghindari resiko kerusakan sensor karena kondisi sungai jika sensor dicelupkan langsung ke sungai. Pada penelitian ini telah dirancang dan diterapkan sistem pengambilan sampel berupa sistem pemompaan air sungai. Sistem pemompaan ini dibuat dengan bahan yang mudah didapatkan di pasaran. Komponen utama dari sistem yang telah dibuat terdiri dari: pompa sentrifugal, tangki sensor, tangki pemancingan pompa,dan solenoid valve. Sistem kontrol pemompaan dibuat menggunakan kontrol konvensional yaitu berupa kombinasi relay dan timer sedangkan input trigger sistem kontrol berasal dari output kontak data logger. Sistem pemompaan sampel air yang telah dibuat pada penelitian ini telah bekerja dengan baik dan memiliki kehandalan yang tinggi. Maintenance yang dibutuhkan dalam sistem ini adalah pembersihan strainer yang tersumbat dikarenakan faktor kondisi sungai.
\end{abstract}

Kata Kunci : sistem pemompaan, kontrol konvensional, pompa, sampel, periode pemompaan sampel

\begin{abstract}
The study of assessment and implementation of Online Water Quality Monitoring System that has been done by Agency for the Assessment and Application of Technology, results a recommendation to develop a water sample system for a certain river conditions. The function of the water sample system is to pump the water from the river to a sensor tank, so that the sensor does not have to be immersed directly into the river. The purpose of this sampling system is to reduce the risks that be faced by the sensor if it is immersed directly into the river. In this research, the water sample system made as a water pumping system. The water pumping system was made from materials that already existed in Indonesian market. The main components of this water pumping system are: centrifugal pump, sensor tank, water tank for the pump, and solenoid valve. The control system for the water pumping system is made from a conventional control consisting of relays and timers and is triggering by the output contact of the data logger. The water pumping systems that have been made in this research is running properly and they have a high reliability. Cleaning a strainers is the only maintenance that is needed for this systems and the frequencies of the maintenance are depend on the water river condition .
\end{abstract}

Keywords: pumping system, conventional control, pump, samples, sampel pumping period

\section{PENDAHULUAN}

\subsection{Latar Belakang}

Seiring bertambahnya penduduk di kota-kota besar maupun di wilayah daerah aliran sungai akan berdampak berupa pencemaran perairan sungai yang cukup besar. Sumber pencemar yang dihasilkan berasal dari buangan limbah domestik maupun limbah industri yang ada di daerah aliran sungai tersebut. Sungai yang semula berfungsi sebagai salah satu komponen siklus hidrologi kini telah beralih fungsi sebagai tempat pembuangan limbah. Ekosistem disekitar sungai yang seharusnya menjadi tempat berlangsungnya siklus hidup organisme kini telah menjadi bangunan tanggul dan jalan inspeksi. Saat ini 
dari 53 sungai di Indonesia, sebesar 73 persen di antaranya telah tercemar (Tempo.CO, 2015). Demi menjaga keseimbangan ekosistem wilayah sungai tersebut, sudah saatnya dilakukan restorasi.

Untuk mendukung rencana restorasi tersebut, KLHK dan BPPT pada tahun 2014 telah melakukan pengkajian dan penerapan teknologi online monitoring kualitas air sungai di Sungai Ciliwung. Peran sistem online monitoring kualitas air ini adalah untuk mempermudah upaya pengendalian pencemaran sungai. Tahun 2015 hingga 2019 BPPT dan KLHK berencana untuk menerapkan sistem online monitoring di beberapa DAS prioritas di Indonesia. Sistem online monitoring yang diterapkan nantinya akan mengacu pada sistem yang telah diujicoba di tahun 2014.

Dalam penelitian di tahun 2014 tersebut telah dihasilkan prototipe sistem online monitoring kualitas air yang diujicobakan di Sungai Ciliwung di halaman Masjid Istiqlal. Komponen utama dari sistem online monitoring tersebut diantaranya: multiprobe sensor beserta LCD handheld, data logger, panel surya, dan baterai. Multiprobe sensor dicelupkan di sungai dengan menggunakan sistem pelampung dan sensor tersebut dilindungi oleh pipa yang telah diberi lubang. Tujuan dari pipa pelindung sensor tersebut adalah untuk melindungi sensor dari benturan langsung terhadap sungai. Data logger berfungsi untuk mengambil data dari sensor dan mengirimkanya ke server yang berada di tempat lain. Panel surya dan baterai merupakan sumber energi listrik utama untuk data logger dan sensor. Pada penelitian tersebut data logger dan baterai ditempatkan ke dalam panel boks outdor yang selanjutnya dipasang dipinggir sungai dengan menggunakan tiang yang terbuat dari besi hollow. Sedangkan panel surya ditempatkan di atas panel boks.

Selama 3 bulan pengujian kendala yang dihadapi adalah dalam hal kondisi sampah dan air sungai. Sungai ciliwung memiliki banyak sampah yang beragam. Sampah yang beragam tersebut terbilang sangat ekstrim karena banyak sampah berukuran besar dan destruktif seperti kayu batangan, peralatan rumah tangga, dan lain-lain. Pada penelitian tersebut telah dilakukan beberapa kali upaya untuk mengatasi masalah sampah yang dikhawatirkan akan merusak sensor yang telah dipasang. Upaya tersebut adalah dengan memperkuat konstruksi pelindung sensor dan dengan membuat penghalang sampah yang dibangun di depan pipa pelindung sensor dari arah aliran sungai. sistem penghalang sampah tersebut sangat handal untuk menghalau sampah-sampah kecil seperti plastik dan ranting dan sampah-sampah yang dihalau tersebut tidak menumpuk di sistem penghalang melainkan kembali terbawa arus ke rute yang tidak melewati sensor. Kekurangan dari sistem penghalang tersebut adalah dibutuhkan konstruksi yang sangat besar dan tidak bisa dibangun jika kondisi sungai tidak memiliki dinding sepadan. Ditambah lagi apabila terdapat sampah-sampah yang berukuran besar seperti kayu gelondongan, sistem penghalau tersebut tidak mampu untuk menghalau yang nantinya akan berakibat merusak sensor atau yang lebih buruk lagi sensor bisa terbawa oleh sampah besar tersebut.

Berdasarkan permasalahan tersebut dibutuhkan alternatif desain sistem online monitoring yang lain yang memiliki resiko kecil. Salah satu alternativnya adalah dengan menggunakan sistem pompa untuk mengambel sampel air dari sungai menuju ke suatu bak yang didalamnya terdapat sensor. Meskipun sistem pemompaan akan memiliki biaya investasi yang lebih besar karena harus membangun bangunan pelindung untuk sistem pompa dan membutuhkan energi listrik yang lebih besar pula, Namun jika dibandingkan dengan resiko kerusakan atau kehilangan sensor, sistem pemompaan sangat layak untuk dipertimbangkan.

\subsection{Tujuan Dan Sasaran}

Tujuan dari penelitian ini adalah merancang sistem pemompaan sampel air dan mengevaluasi penerapanya pada stasiun online monitoring kualitas air.

\section{METODOLOGI}

Metodologi yang digunakan untuk melaksanakan kegiatan ini adalah sebagai mana ditunjukkan oleh Gambar 1 berikut :

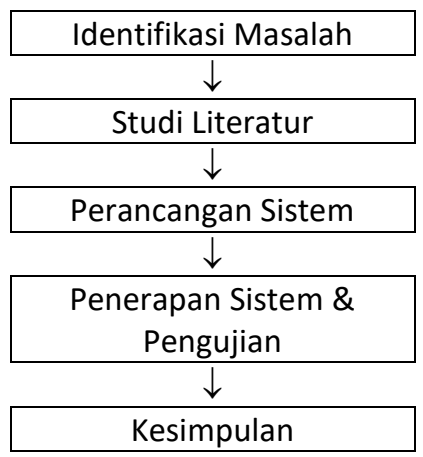

Gambar 1: Metodologi Perancangan Sistem.

- Identifikasi masalah dilakukan dengan studi literatur mengenai permasalahan sensor saat dipasang pada sungai yang kotor.

- Studi literatur dilakukan dengan mengkaji beberapa penerapan sistem sampling yang telah ada yang selanjutnya diaplikasikan sesuai kebutuhan sistem online monitoring kualitas air yang akan dibangun. 
- Perancangan sistem dilakukan dengan membuat DED

- Perancangan desain dilakukan dengan menggunakan software Microsoft Visio dan SketchUp.

- Penerapan \& pengujian sistem pemompaan pada jurnal ini dilakukan di 3 lokasi di Sungai Ciliwung dan 1 lokasi di Sungai Bengawan Solo.

- Simpulan dari penelitian ini adalah evaluasi kehandalan dari sistem pemompaan yang telah diterapkan.

\section{STUDI LITERATUR}

\subsection{Automatic Water Monitoring}

Mijovic et al 2012, melakukan penelitian sistem monitoring kualitas air sungai di serbia menggunakan sistem pompa dan sistem celup langsung. Pada penelitianya di sungai Kolubara, sistem monitoring kualitas air yang dibuat, merupakan sistem online monitoring yang menggunakan pompa untuk mengambil sampel air dari sungai dan selanjutnya dipompa menuju tangki penampung. Pada tangki penampung tersebut telah terdapat beberapa sensor $(\mathrm{pH}$, Conductivity, DO) yang setiap saat mengukur kualitas air yang telah dipompa. Pompa pada sistem tersebut bekerja tersu menerus selama 24 jam sehingga stasiun monitoring tersebut harus memiliki suplai listrik yang terus menerus. Tujuan dari penggunaan sistem pompa pada monitoring tersebut adalah untuk menghindari kerusakan sensor oleh bongkahan es pada sungai jika sensor dicelupkan secara langsung ke dalam sungai. Gambar 1 merupakan contoh sistem monitoring yang mereka terapkan.

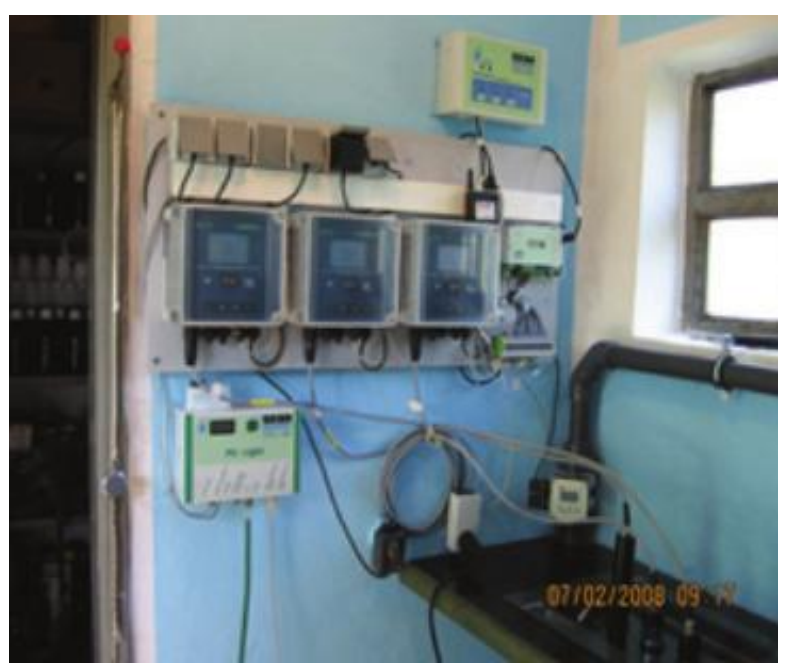

Gambar 1: Sistem Monitoring Kualitas Air di Sungai Kolubara, Serbia (Mijovic et al 2012).
YSI Environmental 2015, melakukan penerapan "Continous Monitoring" di sungai Ohio . Pada sistem tersebut, air sungai dipompa ke dalam tangki yang bangunan pelindung yang berukuran kurang lebih $1,5 \times 1$ meter. Pada tangki tersebut terdapat sensor multiprobe dengan parameter: temperatur, conductivity, $\mathrm{pH}, \mathrm{DO}$, chlorophyll, bluegreen algae, dan turbidity. Air sungai pada sistem tersebut dipompa secara kontinyu menuju tangki dan luapan dari tangki tersebut dikembalikan ke sungai. Penggunaan sistem pompa pada penelitian tersebut dilakukan karena karakteristik sungai yang sering banjir sehingga sangat tidak aman jika sensor dicelupkan secara langsung ke dalam sungai. Simpulan dari penelitian tersebut adalah sistem yang telah dibangun bekerja dengan baik dan dapat mewakili parameter sungai yang sebenarnya. Gambar 2 merupakan gambaran tangki dan sensor di dalam bangunan monitoring.

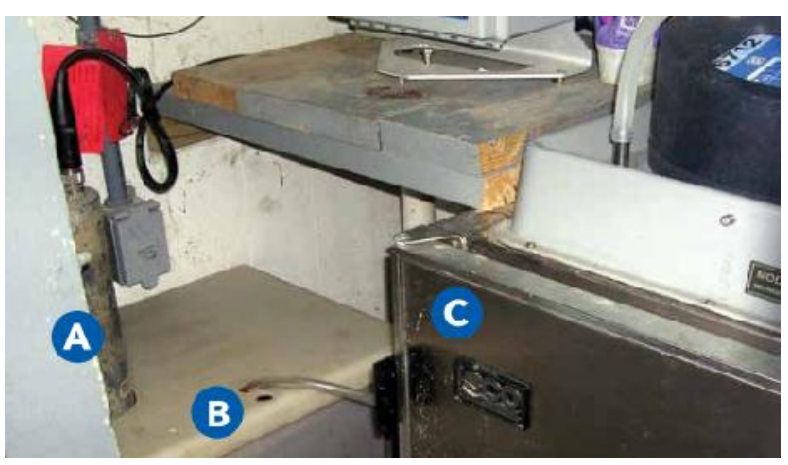

Gambar 2: Sistem Monitoring di Sungai Ohio (A: Sensor, B: Tangki, C: Auto Sampler) (YSI Environmental 2015).

Contoh lain dari sistem monitoring kualitas air sungai yang menggunakan pompa untuk sampling adalah "Riverwatch" yang merupakan produk negara Irlandia. Product tersebut menggunakan beberapa pilihan pompa seperti pompa submersibel, pompa vacum, dan lain-lain.(Fugro, 2009)

\subsection{Kontrol Konvensional}

Sistem kontrol konvensional adalah sistem kendali/kontrol yang menggunakan prinsip elektromekanik. Sistem kontrol jenis ini merupakan sistem kontrol yang sudah kuno namun tetap dipakai sampai sekarang karena dianggap lebih handal dibandingkan dengan sistem kontrol yang menggunakan semi konduktor ataupun digital. Dalam dunia sistem tenaga listrik (Power System), sistem ini masih banyak dijumpai dan lebih dikembangkan kearah perpaduan antara digital (teknologi mikro) dengan konvensional. (S. Galih et al, 2013) 


\subsubsection{Relai}

Relai kontaktor atau biasa disebut "Relai" adalah saklar magnetis yang biasa digunakan dalam kontrol konvensional. Terdiri dari dua bagian utama yakni "koil" dan "kontak". Koil merupakan bagian yang diberi energi listrik agar dapat menggerakkan kontak. Kontak merupakan bagian yang digerakkan koil yang berfungsi sebagai pemutus atau penyambung arus sumber pada peralatan yang dikontrol. Terdapat dua jenis kontak, yakni Normaly Open (NO) dan Normaly Close (NC). Kontak NO akan terbuka (tidak dapat menghantarkan arus) ketika koil tidak diberi suplai daya (de-energized) dan akan tertutup (dapat menhantarkan arus) ketika koil diberi suplai daya (energized). Kontak NC merupakan kebalikan dari kontak NO. Kontak NC akan tertutup (dapat menghantarkan arus) ketika koil tidak diberi suplai daya (de-energized) dan akan terbuka (tidak dapat menghantarkan arus) ketika koil diberi suplai daya (energized).

\subsubsection{Timer}

Timer Relai atau biasa disebut "Timer" adalah saklar tunda yang biasa digunakan sebagai komponen dalam kontrol konvensional. Timer berfungsi untuk mengatur waktu hidup atau mati pada alat yang dikendalikanya. Sama seperti relai, timer terdiri dari koil/powersuplai dan kontak NC dan NO. Timer ini mengendalikan waktu hidup atau mati dari sebuah alat dengan cara menyambung atau memutus arus daya yang menuju alat tersebut. Arus daya yang akan disuplaikan ke sebuah alat dilewatkan/dipasang ke kontak NO/NC.

\subsubsection{Kontaktor}

Kontaktor merupakan saklar elektromagnetik. Sama seperti relai, kontaktor ini terdiri dari koil dan kontak. Perbedaan yang mendasar adalah kapasitas daya yang dimiliki kontak dari kontaktor lebih besar daripada relai. Kontaktor biasa digunakan sebagai saklar pemutus atau penyambung sumber daya utama dari sebuah alat yang biasanya memiliki daya diatas 450 Watt. Kontaktor biasanya memiliki 3 buah kontak utama dan beberapa kontak bantu.

\section{HASIL DAN PEMBAHASAN}

\subsection{Perancangan}

Sistem pemompaan yang dibuat harus memiliki kehandalan yang tinggi baik secara proses maupun sistem kontrolnya. Periode pengukuran sensor yang dibutuhkan oleh KLHK adalah selama 1 jam sekali. Sehingga sistem pompa yang dibuat adalah cukup 1 jam sekali beroperasi. Data logger sistem online monitoring yang dibuat oleh BPPT memiliki 8 port input analog dan 4 port output kontak 12 VDC (dry contact) (S. Galih, 2015). Keempat output kontak tersebut dapat digunakan untuk mengontrol sebuah sistem dari luar sesuai kebutuhan kontrolnya. Pengaturan output kontak dilakukan melalui firmware yang di-download-kan ke microchip data logger. Dalam perancangan ini sistem pemompaan sampling air akan dikontrol menggunakan kontak 12 VDC dari data logger.

Sistem pompa yang dibuat harus memiliki TKDN (Tingkat Konten Dalam Negri) yang tinggi agar duplikasi sistem dapat dilakukan dengan mudah karena memiliki bahan baku yang berasal dari dalam negeri.

\subsubsection{Desain Konseptual Sistem Pemompaan}

Dengan interval pengukuran 1 jam sekali, maka sistem pemompaan dioperasikan sekali dalam 1 jam. Kebutuhan komponen utama dari sistem pompa ini adalah tangki penampung dan sistem pompa. Ukuran tangki penampung harus disesuaikan dengan ukuran sensor dan diusahakan seluruh sensor dapat tercelup. Pompa yang digunakan pada sistem ini adalah pompa sentrifugal karena pompa tersebut paling banyak dijumpai di pasaran dan head yang dimiliki beragam. Kelebihan pompa ini jika dibanding dengan pompa submersibel selain mudah didapat di pasaran adalah kepraktisannya dalam memasang pipa intake. Intake pompa yang digunakan memiliki ukuran yang kecil sehingga mudah untuk dipasang dan tidak mudah tersangkut oleh sampah yang dibawa arus sungai. Sedangkan untuk pompa submersibel, selain jalur intake pompa dan pelindung pompa, yang perlu dibuat juga adalah sistem pengkabelan pompa. Disamping itu pompa submersibel yang ada di pasaran memiliki head yang terbatas yaitu sekitar 8 meter.

Dengan dipilihnya pompa sentrifugal ini maka sistem lain yang dibutuhkan adalah sistem "pemancingan" pompa. Sistem pemancingan pompa secara otomatis harus disiapkan untuk menghindari gagalnya pemompaan karena terdapat kebocoran pada intake sehingga tidak ada air di pipa intake. Sistem pemancingan pompa ini dibuat dengan menggunakan tangki penampung air yang nantinya akan digunakan untuk mengisi pipa intake secara otomatis saat terjadi kebocoran. Gambar 3 merupakan diagram skematik sistem pemompaan yang akan dibuat.

Sistem pemompaan pada Gambar 3 terdiri dari beberapa komponen, yaitu :

- Pompa Sentrifugal

- $\quad$ Solenoid Valve 2 Buah

- Tangki Penampungan 2 Buah

- Check Valve 2 Buah 
- Screen Pipa

- Perpipaan

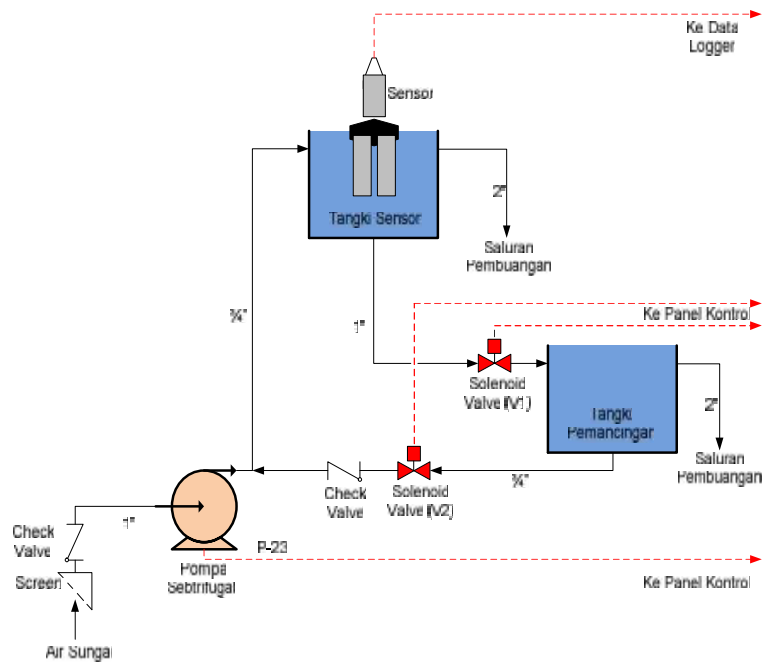

Gambar 3: Desain Skematik Sistem Pemompaan.

Tangki Sensor berfungsi sebagai tempat pengukuran kualitas air. Sensor dipasang di dalam tangki tersebut. Tangki Pemancingan berfungsi sebagai tempat penampungan air yang nantinya akan digunakan untuk mengisi pompa dengan air saat terjadi kebocoran pada pipa intake. Masing-masing tangki terdapat inlet, outlet, dan outlet overflow. Inlet berada di bagian atas, outlet berada di bagian bawah, dan outlet overflow berada di bagian atas. Dalam perancangan sistem ini outlet tangki sensor disalurkan menuju inlet tangki pemancingan yang penyaluranya diatur oleh solenoid valve (V1). Outlet tangki kedua disalurkan menuju pipa intake pompa yang penyaluranya diatur oleh solenoid valve (V2). Overflow masing masing tangki berfungsi untuk mencegah meluapnya air pada tangki penampungan.

Cara kerja sistem pemompaan dalam keadaan steady adalah sebagai berikut :

- Data loger mengirimkan sinyal kepada panel kontrol pompa untuk melakukan pengambilan sampel.

- Kedua buah solenoid terbuka sehingga air dari tangki sensor mengalir menuju tangki pemancingan dan air pada tangki pemancingan ini dialirkan untuk mengisi air pada pipa intake pompa jika terjadi kebocoran.

- Setelah beberapa menit kemudian pompa akan menyala dan akan mengisi tangki sensor. Jika dilihat pada gambar di atas antara tangki pemancingan dan pompa dilengkapi dengan check valve sehingga saat pompa menyala, air tidak akan bisa mengalir menuju tangki pemancingan.

- Beberapa menit pertama saat pompa menyala, kedua solenoid akan tetap terbuka, hal ini bertujuan untuk menghilangkan air bekas yang sebelumnya yang berada pada pipa. Sehingga air yang berada pada tangki sensor merupakan air yang benar-benar langsung dari sungai saat itu juga.

- $\quad$ Saat dipastikan air bekas pada tangki sensor telah terbuang, solenoid kemudian tertup sehingga tangki sensor akan terisi air yang baru.

- Kemudian data logger akan menghentikan sinyal pengambilan sampel sehingga sistem pemompaan berhenti.

- Saat sistem pemompaan berhenti, data logger akan memerintahkan sensor untuk melakukan pengukuran kualitas air di dalam tangki sensor.

\subsubsection{Desain Kontrol Sistem Pemompaan}

Sistem kontrol dibuat berdasarkan kebutuhan sistem pemompaan. Sistem kontrol ini akan dikontrol oleh data logger. Data logger mengontrol sistem dengan cara memberikan sinyal 12 VDC ke panel kontrol sistem pemompaan. Sinyal 12 VDC ini selanjutnya akan menyalakan kontak relay yang selanjutnya akan menghidupkan sistem kontrol pemompaan. Kebutuhan kontrol pada sistem ini adalah Timer yang berfungsi untuk mengatur kapan pompa akan menyala dan untuk mengatur kapan solenoid valve akan tertutup. Sehingga dibutuhkan 2 (dua) buah Timer yakni masing-masing untuk pompa dan untuk solenoid.

Untuk menyalakan pompa dibutuhkan kontaktor sebagai saklar magnetis. Kontaktor ini nantinya akan dikontrol oleh Timer pompa. Dalam perancangan ini pompa diatur oleh kontak Normally Open Timer. Solenoid Valve merupakan komponen dengan kebutuhan daya yang relativ kecil sehingga dalam perancangan ini solenoid valve langsung dikontrol oleh kontak Timer itu sendiri. Dalam perancangan ini solenoid valve diatur oleh kontak Normally Close Timer. Dalam sistem ini pengaman arus yang digunakan berupa MCB yang dipasang pada inline arus. Gambar 4 adalah wiring diagram untuk sistem kontrol pemompaan.

Langkah-langkah kerja sistem kontrol adalah sebagai berikut :

- Data Logger mengirimkan sinyal 12 VDC ke relay.

- Relay selanjutnya akan menhidupkan secara bersamaan Timer 1 (pompa) dan Timer 2 (solenoid).

1. Sesaat setelah relay mengidupkan Timer 2, solenoid akan teraliri listrik (Normally Close) sehingga solenoid akan terbuka, setelah waktu yang ditentukan dalam Timer 2 terpenuhi maka Timer 2 akan memutus arus yang mengalir pada solenoid sehingga solenoid akan kembali tertutup.

2. Sesaat setelah relay mengidupkan Timer 1, pompa belum teraliri listrik hingga waktu 
yang telah ditentukan didalam Timer 1 (Normally Open). Saat waktu terpenuhi, Timer 1 akan menhidupkan kontaktor sehingga pompa akan teraliri arus.

- Data logger menghentikan sinyal 12 VDC. Sehingga proses pemompaan berhenti dan air dalam tangki sensor sudah berganti dengan air yang baru.

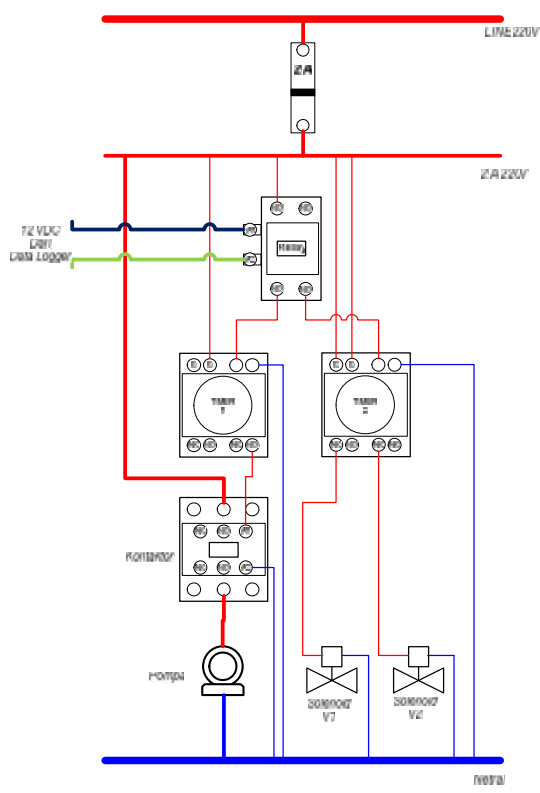

Gambar 4: Wiring Diagram Kontrol Sistem Pemompaan.

Saat proses pemompaan tersebut telah selesai sehingga air dalam tangki sensor sudah berganti dengan air yang baru, selanjutnya data logger akan memerintahkan sensor untuk melakukan pengukuran pada waktu yang telah ditentukan. Pada sistem pemompaan ini air dalam tangki harus ditunggu hingga stabil agar tidak mempengaruhi pembacaan DO karena dikawatirkan dengan dipompaanya air tersebut nilai DO dalam air naik secara signifikan.

\subsection{Penerapan Sistem Pemompaan}

Tangki sensor dibuat dengan bentuk balok ukuran $37 \mathrm{~cm} \times 37 \mathrm{~cm} \times 80 \mathrm{~cm}$. Ukuran tersebut telah disesuaikan dengan ukuran sensor. Sedangkan tangki pemancingan dibuat dengan ukuran yang lebih kecil yaitu $35 \mathrm{~cm}$ x $35 \mathrm{~cm}$ x $50 \mathrm{~cm}$. Gambar 5 . Merupakan sketsa sistem pompa yang dibuat. Tangki sensor diletakkan pada ketinggian di atas tangki pemancingan. Tangki sensor dan tangki pemancingan ini ditopang oleh meja besi dengan ukuran yang disesuaikan dengan ukuran masing-masing tangki.

Penerapan Sistem Online Monitoring Kualitas Air yang dilakukan oleh BPPT dan KLHK ini memiliki interval waktu perekaman data setiap satu jam sekali sehingga sistem pepmompaan sampel akan bekerja setiap satu jam sekali.

Berdasarkan hasil pengujian yang telah dilakukan, durasi pengosongan tangki yang ditetapkan adalah 5 menit, durasi pembilasan tangki 5 menit, dan durasi pengisian adalah 10 menit. Untuk mendapatkan kondisi tersebut, data logger disetting mengeluarkan sinyal selama 20 menit, timer solenoid pengosongan disetting Normally Closed (NC) selama 10 menit, dan timer pompa disetting Normally Open (NO) selama 10 menit. Sedangkan perekaman data dari sensor disetting setelah 30 menit dari kondisi pompa berhenti. Hal tersebut dilakukan untuk menstabilkan kondisi air sungai dalam tangki agar parameterparameter air (khususnya parameter DO) tidak berubah karena melalui proses pemompaan.

Bangunan pelindung dari sistem online monitoring ini berukuran 2 meter x 1,5 meter dengan ketinggian 3 meter. Bangunan yang telah di bangun di 3 lokasi di Sungai Ciliwung dan 1 lokasi di Sungai Bengawan Solo tersebut merupakan bangunan beton permanen dengan pondasi yang telah disesuaikan dengan kondisi tanah sekitar. Gambar 6 merupakan contoh bangunan pelindung pada Sungai Ciliwung segmen Masjid Istiqlal.

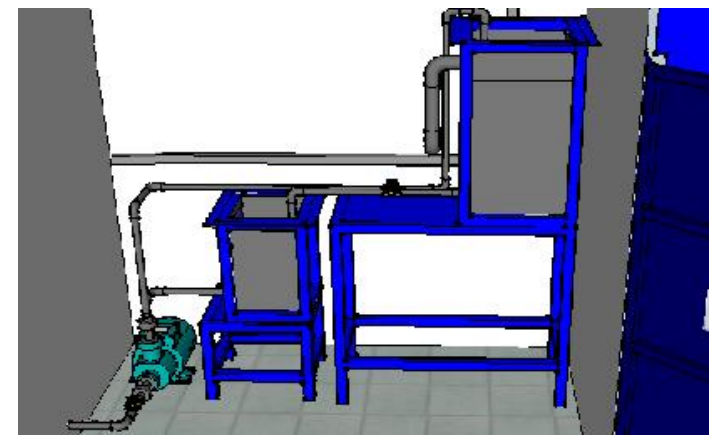

Gambar 5: Sketsa Sistem Pompa.

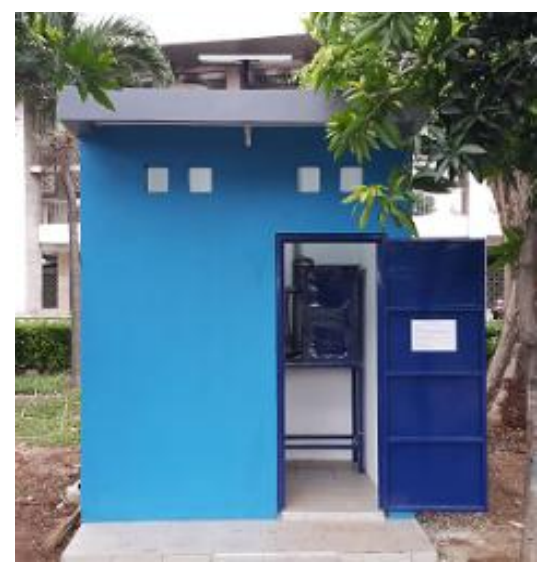

Gambar 6: Bangunan Pelindung Sistem Online Monitoring Di Sungai Ciliwung Segmen Masjid Istiqlal. 
Data logger yang digunakan merupakan perangkat versi paling baru dari data logger yang telah dikembangkan oleh BPPT, yakni versi 3.0. Data logger yang dikembangkan memiliki beberapa fitur utama diantaranya: memiliki sistem pengiriman data berbasis SMS dan dapat lebih dari 164 karakter, interval waktu pengiriman dapat disetting dan dimonitoring dari pusat data, delay waktu pengukuran kualitas untuk early warning system hanya 60 detik, status memori dan status pengiriman data dapat dimonitoring dari pusat data, serta memiliki onsite display untuk menampilkan hasil pengukuran setiap saat di lapangan. Adapun spesifikasi teknis sistem data logger yang dikembangkan adalah (Bayu Budiman dan Heru Dwi Wahjono, 2010) :

- $\quad$ Serial RS-232 port : 1 main, 3 slave

- 8 channel analog port

- 8 bit optocoupler TTL input, extendable to 40 bit

- 4 bit Transistor output, extendable to 20 bit

- 256 kByte flash memori

- Real Time Clock dan

- $\quad$ Dilengkapi PLC untuk EWS

Gambar 7 berikut ini adalah panel data logger yang telah terpasang pada bangunan sistem online monitoring Sungai Ciliwung Segmen Kelapa Dua. Panel data logger berisi logger, baterai dan handheld sensor.

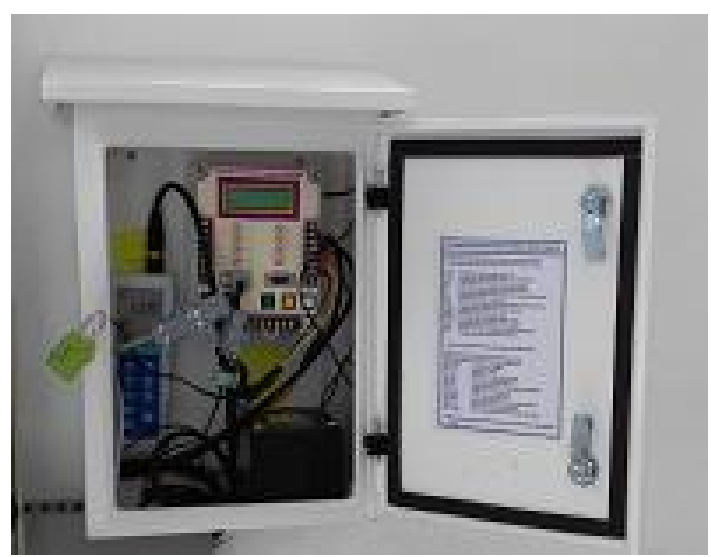

Gambar 7: Panel Data Logger.

Panel kontrol sistem pemompaan dibuat dengan menggunakan panel boks berukuran $20 \mathrm{~cm} x$ $30 \mathrm{~cm} \times 20 \mathrm{~cm}$. Panel tersebut berisi sebuah kontaktor, sebuah relay 12 VDC, dan 2 buah Timer. Panel kontrol yang telah dibuat dapat dioperasikan secara manual yaitu menggukan 2 selector switch yang telah terpasang yang berfungsi untuk menghidupkan dan mematikan pompa dan solenoid valve. Tujuan dari pengoperasian manual ini adalah untuk memudahkan pengujian saat dilakukanya maintenance. Gambar 8 merupakan panel kontrol sistem pemompaan yang telah dibuat dan terpasang pada bangunan sistem online monitoring Sungai Ciliwung Segmen Kelapa Dua.

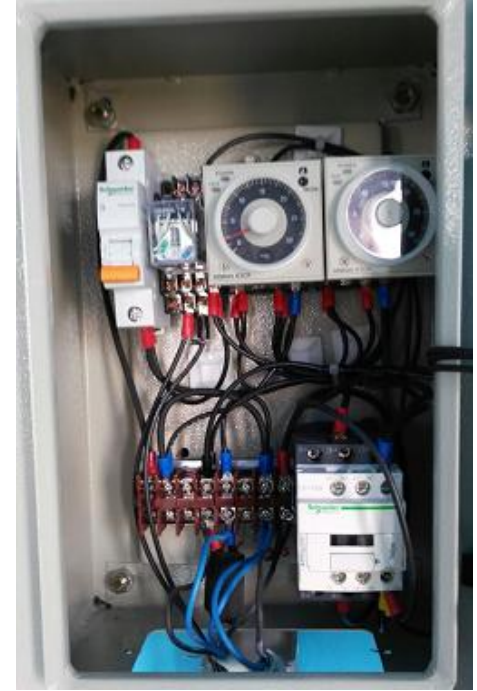

Gambar 8: Panel Kontrol Sistem Pemompaan.

Dalam sistem online monitoring ini, sensor yang digunakan adalah sensor multiprobe DKK-TOA WQC-24 dengan 12 parameter pengukuran diantaranya: Temperatur, Conductivity, TDS, Salinity, DO, pH, Turbidity, Depth, SwSG, Ammonium, Nitrate, ORP.. Gambar 9 merupakan sensor multiprobe DKKTOA WQC-24.

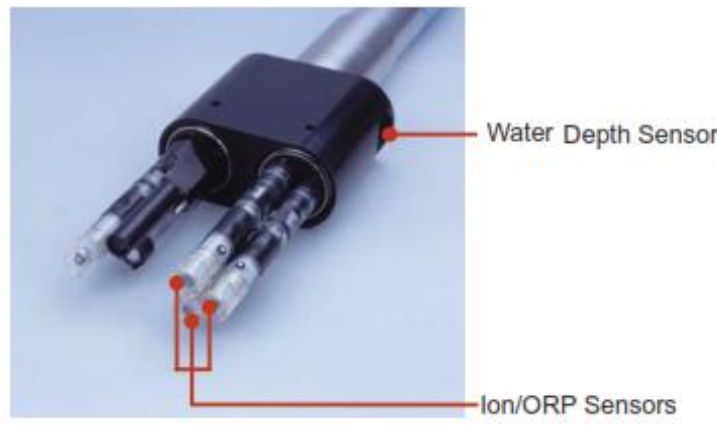

Gambar 9 : Sensor WQC-24 (TOA-DKK, 2015).

\subsubsection{Lokasi Sungai Ciliwung Segmen Masjid Istiqlal}

Lokasi pemasangan sistem online monitoring segmen Masjid Istiqlal berada pada bagian sungai Ciliwung yang melintas di halaman Masjid Istiqlal dengan koordinat $6.171404{ }^{\circ} \mathrm{S}, 106.931097{ }^{\circ} \mathrm{E}$. lokasi ini berada di sebelah barat jembantan pintu selatan komplek.

Pompa yang digunakan pada sistem ini merupakan pompa semijet dengan sucktion head sebesar 11 meter. Jarak intake pompa dengan bangunan pelindung kurang lebih adalah sebesar 15 meter dengan elevasi kurang lebih 5 meter. Gambar 10 merupakan kondisi tangki sensor saat pengujian sistem pemompaan. Gambar 11 merupakan kondisi pipa intake dan pipa overflow pada lokasi sistem online monitoring ini. 


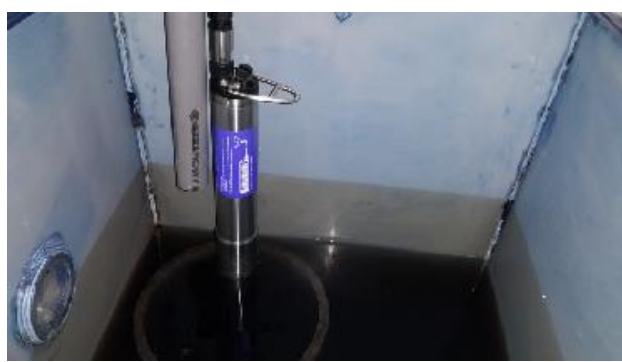

Gambar 10: Tangki Sensor Saat Sistem Pemompaan Berjalan.

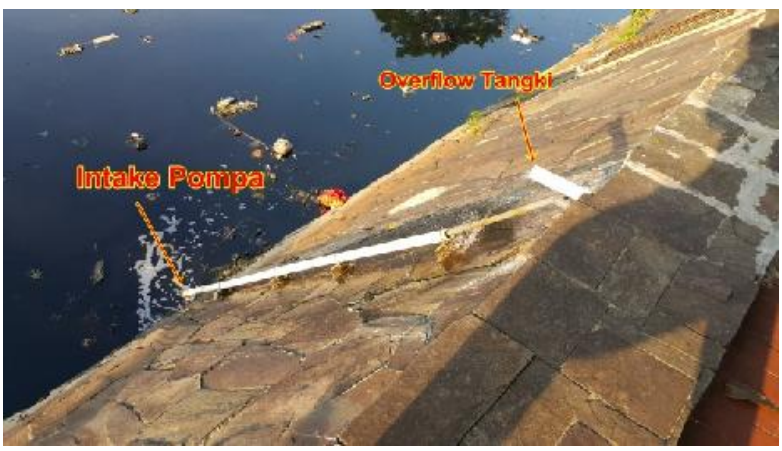

Gambar 11: Kondisi Intake Pompa dan Tangki Overflow Sistem Online Monitoring Segmen Istiqlal.

\subsubsection{Lokasi Sungai Ciliwung Segmen Manggarai}

Lokasi pemasangan sistem online monitoring segmen Manggarai berada pada bagian sungai Ciliwung yang melintas di Pintu Air Manggarai dengan koordinat $6.20770^{\circ} \mathrm{S}, 106.84910^{\circ} \mathrm{E}$. lokasi ini berada di belakang bangunan kontrol pintu air.

Pompa yang digunakan pada sistem ini merupakan pompa semijet dengan sucktion head sebesar 11 meter. Jarak intake pompa dengan bangunan pelindung kurang lebih adalah sebesar 8 meter dengan elevasi kurang lebih 6 meter. Gambar 12 merupakan kondisi tangki sensor saat pengujian sistem pemompaan. Gambar 13 merupakan kondisi bangunan, pipa intake dan pipa overflow pada lokasi sistem online monitoring ini.

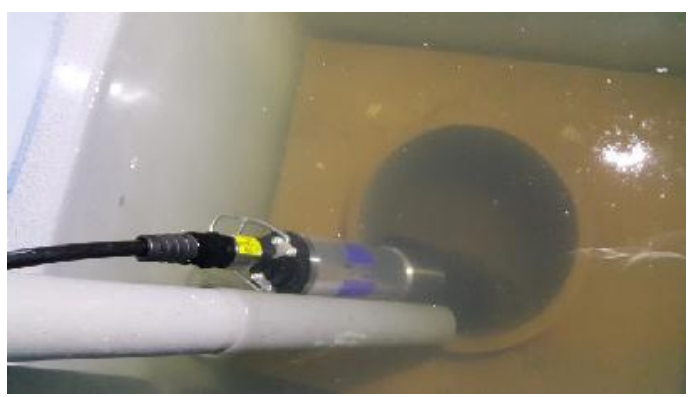

Gambar 12: Tangki Sensor Saat Sistem Pemompaan Berjalan.

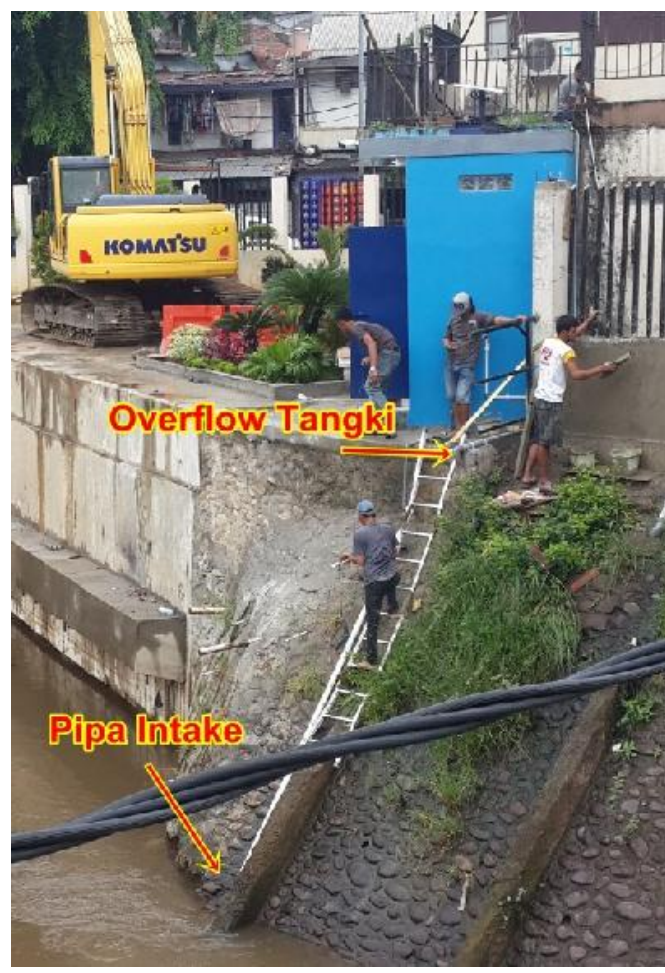

Gambar 13: Kondisi Intake Pompa dan Tangki Overflow Sistem Online Monitoring Segmen Manggarai.

\subsubsection{Lokasi Sungai Ciliwung Segmen Kelapa Dua}

Lokasi pemasangan sistem online monitoring segmen Kelapa Dua berada pada bagian sungai Ciliwung yang melintas basecamp masyarakat pecinta ciliwung "Mat Pecl" dengan koordinat $6.35279^{\circ} \mathrm{S}$, 106.83563 E.

Pompa yang digunakan pada sistem ini merupakan pompa semijet dengan sucktion head sebesar 11 meter. Jarak intake pompa dengan bangunan pelindung kurang lebih adalah sebesar 15 meter dengan elevasi kurang lebih 8 meter. Gambar 14 merupakan kondisi tangki sensor saat pengujian sistem pemompaan. Gambar 15 merupakan kondisi pipa intake dan pipa overflow pada lokasi sistem online monitoring ini.

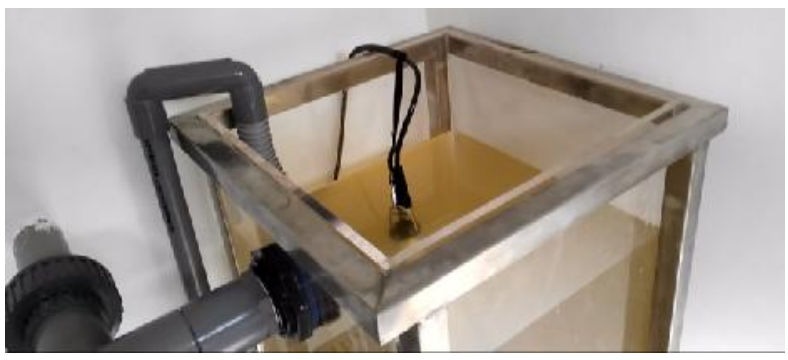

Gambar 14: Tangki Sensor Saat Sistem Pemompaan Berjalan. 


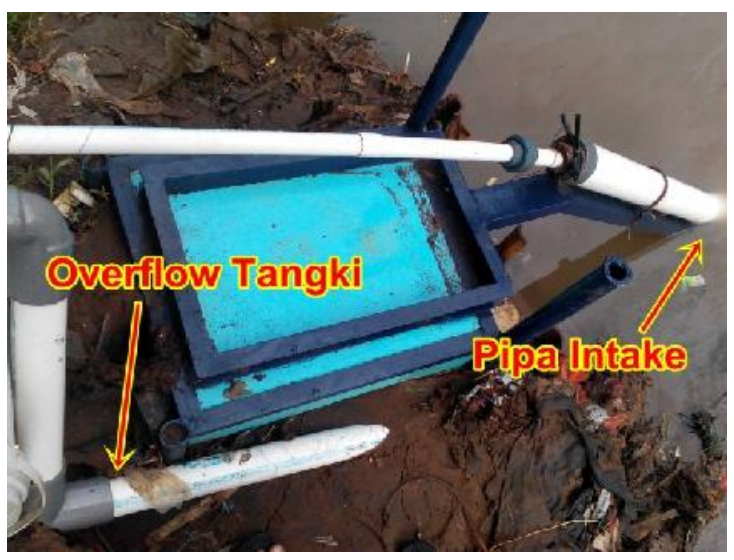

Gambar 15: Kondisi Intake Pompa dan Tangki Overflow Sistem Online Monitoring Segmen Kelapa Dua.

\subsubsection{Lokasi Sungai Bengawan Solo, Bendung Colo}

Lokasi pemasangan sistem online monitoring Bendung Colo berada pada bagian Sungai Bengawan Solo yang melintasi Bendung Colo dengan koordinat $7.75145^{\circ} \mathrm{S}, 110.9011^{\circ} \mathrm{E}$. Lokasi bangunan pelindung pada sistem ini berada pada lingkungan kantor Perum Jasa Tirta 1 dengan jarak kurang lebih 100 meter dari sungai.

Pompa yang digunakan pada sistem ini merupakan pompa semijet dengan sucktion head sebesar 11 meter. Jarak intake pompa dengan bangunan pelindung kurang lebih adalah sebesar 100 meter dengan elevasi kurang lebih 10 meter. Khusus pada sistem pemompaan ini, pompa dipasang di dekat sungai, karena jarak bangunan yang terlalu panjang sehingga dikawatirkan pompa tidak mampu untuk melakukan sucktion. Pompa diletakkan pada rumah pompa yang dibuat menggunakan konstruksi beton dengan ukuran yang telah disesuaikan dengan pompa. Gambar 16 merupakan kondisi tangki sensor saat pengujian sistem pemompaan. Gambar 17 merupakan kondisi pompa, pipa intake dan pipa overflow pada lokasi sistem online monitoring ini.

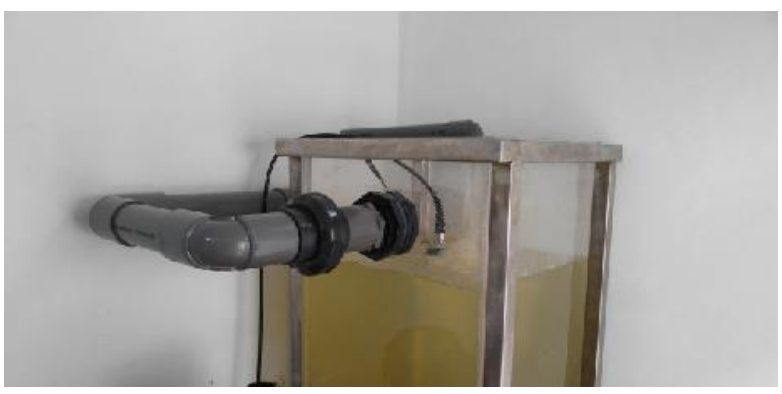

Gambar 16: Tangki Sensor Saat Sistem Pemompaan Berjalan.

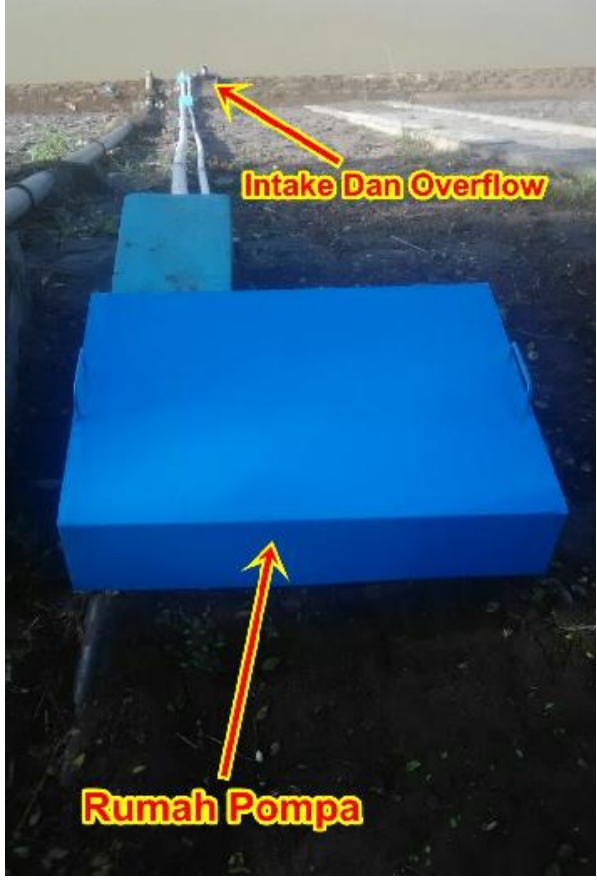

Gambar 17: Kondisi Pompa, Intake Pompa dan Tangki Overflow Sistem Online Monitoring Segmen Kelapa Dua.

\subsection{Kondisi Sistem Pemompaan Dari Awal Hingga Saat Ini \\ Sistem online monitoring Sungai Ciliwung} segmen Masjid Istiqlal dan segmen Manggarai telah dibangun pada bulan Desember 2015 sedangkan sistem online monitoring Sungai Ciliwung segmen Kelapa Dua dan sistem online monitoring Sungai Bengawan Solo pada Bendung Colo telah dibangun pada bulan Agustus 2016.

Keseluruhan sistem pemompaan hingga saat ini telah beroprasi dengan baik dan sesuai keinginan. Beberapa maintenance yang sudah dilakukan adalah penggantian strainer intake pompa pada sistem online monitoring segmen Istiqlal dan Manggarai. Penggantian strainer tersebut dilakukan karena strainer yang telah dipasang sebelumnya mudah tersumbat oleh kotoran. Strainer pengganti memiliki ukuran yang lebih besar sehingga tidak mudah tersumbat oleh kotoran sungai

\section{KESIMPULAN}

Kesimpulan yang dapat diambil dari kegiatan perancangan dan penerapan sistem pemompaan sampel air untuk sistem online monitoring kualitas air adalah sebagai berikut:

- $\quad$ Sistem pemompaan dibuat dengan bahan yang mudah didapat di pasaran

- Komponen utama sistem pemompaan yang dibangun terdiri dari pompa sentrifugal, tangki sensor, tangki pemancingan pompa, dan solenoid valve. 
- $\quad$ Sistem kontrol pemompaan dibuat menggunakan kontrol konvensional yaitu berupa kombinasi relay dan timer sedangkan input trigger sistem kontrol berasal dari output kontak data logger.

- $\quad$ Sistem pemompaan sampel air yang telah dibuat, telah bekerja dengan baik dan memiliki kehandalan yang tinggi.

- Maintenance yang dibutuhkan dalam sistem ini adalah pembersihan strainer yang tersumbat dikarenakan faktor kondisi sungai.

\section{SARAN}

- Untuk pengembangan lebih lanjut, perlu dikembangkan sistem pengambilan sampel dengan volume air sampel yang lebih sedikit sehingga lebih hemat energi.

- Untuk daerah terpencil yang tidak memiliki suplai listrik dari PLN, sumber listrik sistem pemompaan dapat menggunakan energi surya dengan memanfaatkan atap untuk peletakan panel suryanya.

\section{DAFTAR PUSTAKA}

- Mijovic Svetomir, Palmar Bojan. 2012. Water Quality Monitoring Automation of Rivers in Serbia. Facta Universitatis, Working and Living Environtmental Protection Vol. 9, $\mathrm{N}^{0} 1,2012$, pp. 1 -10 .
- YSI Environmental. 2015. Continous Monitoring of Turbidity in Ohio Rivers Using Modified Sidestream Method. YSI Environmental. Aplication Note A574.

- Fugro. 2009. Riverwatch Field Station. Brosur. Fugro GEOS Ltd, Wallingford, UK.

- S. Galih, H. Singgih, Sunarno. 2013. Perancangan Sistem Otomasi Genset-LPG sebagai Penyedia Daya Darurat Di Puskesmas Patuk 1 Gunungkidul. Jurusan Teknik Fisika, Universitas Gadjah Mada.

- S. Galih dan Heru D. W.. 2015. Instalasi Sistem Pemantauan Kualitas Air Online Berbasis GSM di Sungai Ciliwung Segmen Istiqlal. Pusat Teknologi Lingkungan BPPT. JAI Vol. 8 No. 1, 2015

- B. Bayu dan Heru D. W.. 2010 Petunjuk Operasional Sistem Onlimo Sungai Kapuas, Pusat Teknonologi Lingkungan - BPPT

- W.,Heru Dwi dan Bayu Budiman. 2006. Sistem Manajemen Komunikasi Data Jarak Jauh Berbasis Teknologi SMS dan Radio Telemetri Untuk Pemantauan Kualtias Air, Jurnal Teknologi Lingkungan Vol 7 No. 2 Mei 2006

- TOA-DKK Corporation. 2015. Dokumen Teknis, Water Quality Meter Model WQC-24

- $\quad$ BPPT Enjiniring. 2016. Dokumen Teknis, Laporan Akhir. Pemasangan Alat Monitoring Online Sistem Di Ciliwung (1 Titik), Di Cisadane (2 Titik), Di Serayu (2 Titik), Dan Di Bengawan Solo (2 Titik). 